\section{Follow the follistatin}

\section{By Tim Fulmer, Staff Writer}

Attempts to treat muscular dystrophy have generally followed one of two paths, neither of which has yet reached the market. One option is delivering the dystrophin protein that is missing or dysfunctional via gene or cell therapy. The other is inhibiting myostatin, a negative regulator of muscle growth. ${ }^{1}$ Now a study published in the Proceedings of the National Academy of Sciences combines the two approaches, using gene therapy to deliver follistatin, a myostatin inhibitor, to diseased muscle.

There are no approved drugs for the disease, and last month's discontinuation of Wyeth's MYO-029 antimyostatin antibody was just the latest stumble for companies in search of a treatment for muscular dystrophy (MD).

More than two decades ago, scientists determined that mutations in the dystrophin gene $D M D$ cause most types of MD. The most common form is Duchenne muscular dystrophy (DMD), which affects 1 in 3,500 male births and results from an absence of dystrophin or the expression of nonfunctional dystrophin.

DMD typically follows a course of progressive muscle weakness starting in early childhood that can lead to death by early adulthood, usually as a result of respiratory or cardiac dysfunction. ${ }^{2,3}$

The research published in PNAS by scientists at Ohio State University and Nationwide Children's Hospital builds on previous work in transgenic mice by Se-Jin Lee and colleagues at the Johns Hopkins School of Medicine that identified a link between follistatin overexpression and increased muscle. ${ }^{4,5}$ The new findings show that a single administration of the gene coding for follistatin protein increased hind limb muscle mass, total body mass and hind limb grip strength in wild-type mice at two years compared with animals that received a gene encoding green fluorescent protein (GFP) control protein. ${ }^{6}$

Similar trends were seen in $d m d$ mouse models of DMD that received a single follistatin injection at three weeks of age and were then evaluated at six months. The increases in muscle mass were dose dependent.

Finally, adult mice that received follistatin at 210 days of age had less inflammation and fibrosis in the diaphragm and calf muscle when they were 560 days old than did mice that received control GFP.

Brian Kaspar, principal investigator and corresponding author on the PNAS paper, told SciBX that "based on follistatin's positive effects on inflammation and fibrosis, in addition to increasing muscle mass and strength, the protein could be potentially useful for treating older Duchenne muscular dystrophy patients." Kaspar is assistant professor of pediatrics at Ohio State and a principal investigator at The Research Institute at Nationwide Children's Hospital.

Jerry Mendell, a coauthor on the PNAS paper, added that "because it is unlikely that one treatment approach will ever apply to all muscular dystrophy patients, we are interested in next looking at follistatin in combination with other therapies in development, such as dystrophin gene-replacement therapy. This could be one approach to treating muscular dystrophy in older patients." Mendell is a professor of pediatrics at Ohio State and director of the Center for Gene Therapy at Nationwide Children's Hospital.

\section{Testing the concept}

Academics polled by SciBX hope that follistatin will produce stronger results than other myostatin inhibitors, none of which have yet succeeded in the clinic.

A case in point is Wyeth's announcement in March that it would not continue development of MYO-029 for MD after Phase I/II data in 116 adults with MD published in the Annals of Neurology showed "no improvements noted in exploratory endpoints of muscle strength and function."

The data stood in contrast to Wyeth's preclinical research, which showed significantly greater muscle mass $(p<0.0001)$ and better muscle strength $(p<0.003)$ in mouse models of DMD than in mice that received vehicle control. $^{8}$

In a Phase I/II study, the compound was safe and well tolerated. Wyeth spokesperson Michael Lampe told SciBX the pharma company "will continue to explore myostatin inhibition along with other strategies" to treat muscle diseases (see Table 1, “Muscular dys-

\section{trophy pipeline").}

Referring back to the PNAS paper, Daniel Greenspan, professor in the Department of Pathology and Laboratory Medicine at the University of Wisconsin-Madison, told SciBX that "muscle is a good target tissue for the gene-therapy approach, as the delivered gene is likely to stay put" in that tissue type.

He added that "an interesting feature of the results is that remote muscles are also affected, in addition to the injected muscle, suggesting that this approach might have a body-wide effect on MD patients."

Lee, one of the scientists who first identified myostatin, ${ }^{9}$ told SciBX that "the new paper is important for two reasons. It shows definitively that follistatin can induce muscle growth in adult mice, which was only implied before. And second, it suggests that systemic effects on muscle growth can be achieved even when follistatin is being produced at just a couple of sites in the body." Lee is a professor of molecular biology and genetics at Johns Hopkins. 


\section{TARGETS \& MECHANISMS}

Table 1. Muscular dystrophy pipeline. Selected compounds in development for muscular dystrophy (MD).

\begin{tabular}{|c|c|c|c|c|}
\hline Company & Product & Description & Indication & Status \\
\hline Insmed Inc. (NASDAQ:INSM) & $\begin{array}{l}\text { iPlex mecasermin } \\
\text { rinfabate }\end{array}$ & $\begin{array}{l}\text { Complex of insulin-like growth factor- } 1 \text { and its } \\
\text { principal binding protein insulin-like growth factor } \\
\text { binding protein-3 }\end{array}$ & Myotonic MD & Phase III \\
\hline PTC Therapeutics Inc. & PTC124 & $\begin{array}{l}\text { Small molecule that facilitates complete translation } \\
\text { of proteins containing nonsense mutations }\end{array}$ & $\begin{array}{l}\text { Duchenne MD } \\
\text { (DMD) }\end{array}$ & Phase II \\
\hline $\begin{array}{l}\text { Santhera Pharmaceuticals Holding AG } \\
\text { (SWX:SANN)/Takeda Pharmaceutical Co. Ltd. } \\
\text { (Tokyo:4502) }\end{array}$ & $\begin{array}{l}\text { Idebenone } \\
\text { (SNT-MC17) }\end{array}$ & Membrane-associated antioxidant & DMD & Phase II \\
\hline AVI BioPharma Inc. (NASDAQ:AVII) & AVI-4658 & $\begin{array}{l}\text { Neugene antisense oligonucleotide targeting exon } \\
51 \text { of the } D M D \text { gene }\end{array}$ & DMD & Phase I/II \\
\hline Prosensa B.V. & PRO051 & $\begin{array}{l}\text { Antisense oligonucleotide that induces the skipping } \\
\text { of exon } 51 \text { of the } D M D \text { gene }\end{array}$ & DMD & Phase I/II \\
\hline Acceleron Pharma Inc. & ACE-031 & Myostatin (GDF-8) inhibitor & $\mathrm{MD}$ & Preclinical \\
\hline Faust Pharmaceuticals S.A. & FP0023 & Utrophin inducer & DMD & Preclinical \\
\hline $\begin{array}{l}\text { Mirus Bio Corp./Transgene S.A. } \\
\text { (Euronext:Transgene) }\end{array}$ & MyoDys & $\begin{array}{l}\text { Plasmid DNA encoding the full-length human } \\
D M D \text { gene }\end{array}$ & $\mathrm{MD}$ & Preclinical \\
\hline Summit Corp. plc (LSE:SUMM) & SMT C1100 & Small molecule that upregulates utrophin & DMD & Preclinical \\
\hline
\end{tabular}

Lee hypothesized that because follistatin binds myostatin in addition to a number of related ligands, it has a higher likelihood of producing more dramatic results in humans than Wyeth's MYO-029. "Given that it is now clear that other TGF- $\beta$ [superfamily] members besides myostatin also function to limit muscle growth, an inhibitor like follistatin could have greater potential for promoting muscle growth," he said.

Lee did note additional research first needs to address the question of "whether there will be effects of follistatin outside of the muscle." Indeed, he said, because follistatin binds multiple ligands, "there is also the potential disadvantage of undesired side effects in other tissues."

Greenspan agreed: "A concern with follistatin is that it will affect activin and perhaps other TGF- $\beta$-like ligands as well." Potential adverse effects might have been too subtle to pick up in the current study but might show up in humans, he said.

Members of the transforming growth factor- $\beta$ (TGF- $\beta$ ) superfamily are cell-signaling peptides involved in multiple cellular pathways that potentially affect cellular proliferation and differentiation. ${ }^{10}$

Greenspan also thinks "initial studies should employ recombinant follistatin rather than gene therapy, as the former course would be more easily reversible in case of adverse side effects."

One area of concern was determining the appropriate animal models for further exploration of the safety and efficacy of follistatin.

H. Lee Sweeney, professor of physiology at the University of Pennsylvania School of Medicine, told SciBX that animal models other than rodents might be the only tools capable of predicting potential off-target toxicities in humans.

Sweeney said mouse models of efficacy lack predictive power. "The fact that dystrophic mice have skewed muscle fiber types and limit- less regenerative capacity compared with humans makes them poor predictors of drug efficacy," he said.

Part of Sweeney's research is now focused on using dogs to investigate the molecular mechanism of myostatin inhibition in DMD.

"Dystrophic canine models better approximate human physiology - not only because dogs have muscle fiber types more similar to humans, but also because canine forms of muscular dystrophy are of greater severity and have more cardiac involvement than what's seen in mice," he said. "The longer life span of dogs also allows for better investigation of late-stage disease than what's typically possible in mice."

Lorenzo Puri, a professor at the Burnham Institute for Medical Research, agreed. $\mathrm{He}$ wants to see "more convincing evidence that follistatin has a beneficial effect on late-stage dystrophic muscles, that is, on fibrosis."

Thus, he said, it would be necessary "to explore the role of follistatin in more reliable animal models of DMD-the dystrophic dogs."

Puri's group is using dogs to study the potential for histone deacetylase (HDAC) inhibitors to treat muscular dystrophies. Previously, they found that HDAC inhibitors such as trichostatin A increase myofiber size in dystrophin-deficient mice by inducing follistatin expression in certain myogenic precursor cells known as satellite cells. ${ }^{11}$

\section{Fixing the defect}

Although some companies in the MD space think compounds such as follistatin are taking the right approach, others are seeking to fix the underlying genetic defect.

Acceleron Pharma Inc. is in the former camp. The company's ACE-031 is a fusion protein consisting of the extracellular portion of myostatin's endogenous receptor, activin receptor type IIB, linked 


\section{TARGETS \& MECHANISMS}

to a human IgG1 Fc domain to create a soluble, systemically active compound.

CSO Jasbir Seehra described ACE-031 as a "ligand trap that potentially binds multiple negative regulators of muscle in addition to myostatin, although it should be more selective than follistatin."

ACE-031 has shown efficacy in dystrophic rodent models and in primates, Seehra said, and is expected to start a Phase I trial this year.

No matter what molecules are used to inhibit myostatin, one potential drawback is that the underlying defects in the gene which cause DMD are not addressed by the strategy, said Thomas Meier, CSO of Santhera Pharmaceuticals Holding AG.

"Myostatin inhibition may increase muscle mass in the patient, but because the dystrophin defects still exist, the muscle fibers remain vulnerable to injury. Inhibiting myostatin could thus lead to short-term functional gains that, over the long term, are lost as muscles use up their capacity to repair the regular damage that occurs during muscle activity," he said.

Meier also noted that recent work in myostatin-deficient mice published by John Faulkner and colleagues at the University of Michigan School of Medicine suggests that increasing muscle mass using myostatin inhibitors could negatively affect tendons. ${ }^{12}$

Santhera's approach is to target defective energy homeostasis in diseased muscle cells. The company's lead compound, SNT-MC17, is an antioxidant and electron carrier that targets mitochondrial ATP deficiency, which occurs in the muscle cells of DMD patients.

In a double-blind, placebo-controlled Phase II trial in 21 boys with DMD, the orally administered derivative of natural coenzyme Q10 produced improvements in cardiac and respiratory function after one year, Meier said.

Stuart Peltz, president and CEO of PTC Therapeutics Inc., told SciBX that his company's approach targets genetic mutations in the $D M D$ gene that give rise to disease pathology in the first place.

In muscle cultures from DMD patients and dystrophin-deficient mice, the small molecule PTC124 suppressed nonsense alleles of the
DMD gene, which led to production of full-length dystrophin. PTC124 also rescued striated muscle function in dystrophin-deficient mice within two to eight weeks. ${ }^{13}$

Last October, PTC Therapeutics reported interim results from a Phase II trial, in which PTC124 increased dystrophin expression in 18 of 38 patients with DMD due to a nonsense mutation.

PTC124 has Fast Track designation in the U.S. and Orphan Drug designations for nonsense mutation-related DMD and cystic fibrosis in the U.S. and EU.

\section{REFERENCES}

1. Chakkalakal, J. et al. FASEB J. 19, 880-891 (2005)

2. Davies, K. \& Nowak, K. Nat. Rev. Mol. Cell Biol. 7, 762-773 (2006)

3. Lim, L. \& Rando, T. Nat. Clin. Pract. Neurol. 4, 149-158 (2008)

4. Lee, S.-J. \& McPherron, A. Proc. Natl. Acad. Sci. USA 98, 9306-9311 (2001)

5. Lee, S.-J. PLoS ONE 2, e789; published online Aug. 29, 2007; doi:10.1371/journal.pone.0000789

6. Haidet, A. et al. Proc. Natl. Acad. Sci. USA; published online 11 March 2008;

doi:10.1073/pnas.0709144105

Contact: Brian Kaspar, The Research Institute, Nationwide Children's Hospital, Columbus, Ohio e-mail: kasparb@ccri.net

7. Wagner, K. et al. Ann. Neurol. 63, 1-11 (2008)

8. Bogdanovich, S. et al. Nature 420, 418-421 (2002)

9. McPherron, A. et al. Nature 387, 83-90 (1997)

10. ten Dyke, P. \& Arthur, H. Nat. Rev. Mol. Cell Biol. 8, 857-869 (2007)

11. Minetti, G. et al. Nat. Med. 12, 1147-1150 (2006)

12. Mendias, C. et al. Proc. Natl. Acad. Sci. USA 105, 388-393 (2008)

13. Welch, E. et al. Nature 447, 87-93 (2007)

\section{COMPANIES AND INSTITUTIONS MENTIONED}

Acceleron Pharma Inc., Cambridge, Mass.

Burnham Institute for Medical Research, La Jolla, Calif.

Johns Hopkins School of Medicine, Baltimore, Md.

Nationwide Children's Hospital, Columbus, Ohio

Ohio State University, Columbus, Ohio

PTC Therapeutics Inc., South Plainfield, N.J.

Santhera Pharmaceuticals Holding AG (SWX:SANN), Liestal, Switzerland

University of Michigan School of Medicine, Ann Arbor, Mich.

University of Pennsylvania School of Medicine, Philadelphia, Pa. University of Wisconsin-Madison, Madison, Wis.

Wyeth (NYSE:WYE), Madison, N.J. 